\title{
Neurological involvement in the epidermal naevus syndrome
}

\author{
D. L. Mc A U LEY, D. A. IS E B B R G, A N D W. G O O D D Y \\ From the National Hospital for Nervous Discases, Queen Square, London
}

SUMMARY The case of a left handed girl aged 18 years suffering from the "epidermal naevus syndrome" is described. She presented with dysphasia, transient left hemiparesis, and sensory symptoms due to an occlusion of the right internal carotid artery. Arterial occlusion, abnormal retinal vessels, and Raynaud's phenomenon have not been previously documented. The neurological complications of this syndrome are discussed. It is suggested that the arterial occlusion may have been caused by a dysplastic artery.

The congenital neurocutaneous syndromes (phakomatoses) are well-known. Their relationship to the "epidermal naevus syndrome" is uncertain. It has been suggested that they should all be grouped as the neurocutaneous dysgeneses (Von Schimmelpennig, 1957; Holden and Dekaban, 1972). The syndrome consists of congenital naevi in association with skeletal, dental, neural, ocular, vascular, renal, and cardiac abnormalities. There is an increased incidence of malignancies of various origins, and recognition is important for this reason (Solomon and Esterly, 1975). We describe a patient presenting with neurological complications although most of the naevus had previously been removed surgically.

\section{Case report}

An eighteen year old, left handed girl developed a sudden, severe, right sided headache, expressive dysphasia, and left sided paraesthesiae on 29 March 1977. During the night she was incontinent of urine. The next morning she was still severely dysphasic, with mild left hemiparesis and dysgraphia which persisted for two days until they started to improve.

She had been born with an extensive birth mark affecting the right side of her body for which she had undergone five plastic surgery operations. Swollen hands and Raynaud's phenomenon de-

\footnotetext{
Address for reprint requests: Dr D. A. Isenberg, Medical Registrar University College Hospital, University College Hospital, Gower Street, London WC1, England.

Accented 22 November 1977
}

veloped at the agc of three years. At the age of six years she had pericarditis and congestive heart failure with what were described as pneumonia, pleural effusion, and persistent collapse of the right lower lobe with pleural thickening. A right heart catheterisation done subsequently was normal but a selective angiocardiogram showed collapse of the middle and lower lobes of the right lung with obstruction of the arteries to these lobes and irregular stenosis of the right upper lobe artery. The right main pulmonary artery was small.

When aged eight years, a large squamous papilloma was removed from the soft palate. Eight months before this admission, after investigation for ankle oedema, a protein-losing enteropathy due to intestinal lymphangiectasia was discovered. This disorder had remitted spontaneously.

An elder brother had been born with a "withered right arm" which was subsequently amputated.

On examination the patient was a small girl with a well-demarcated erythematous area on the right side of her forehead, just crossing the midline. There were two hairless areas of naevus in the scalp over the right parietal region. Figure 1 shows the full extent of her birth mark. Most of the original lesion had bcen cxcised. The remainder was brown and warty in appearance with a small vascular component in a few areas.

Her right forearm was longer than the left although the right side of the face was smaller than the left. The left hand showed Raynaud's phenomenon. 


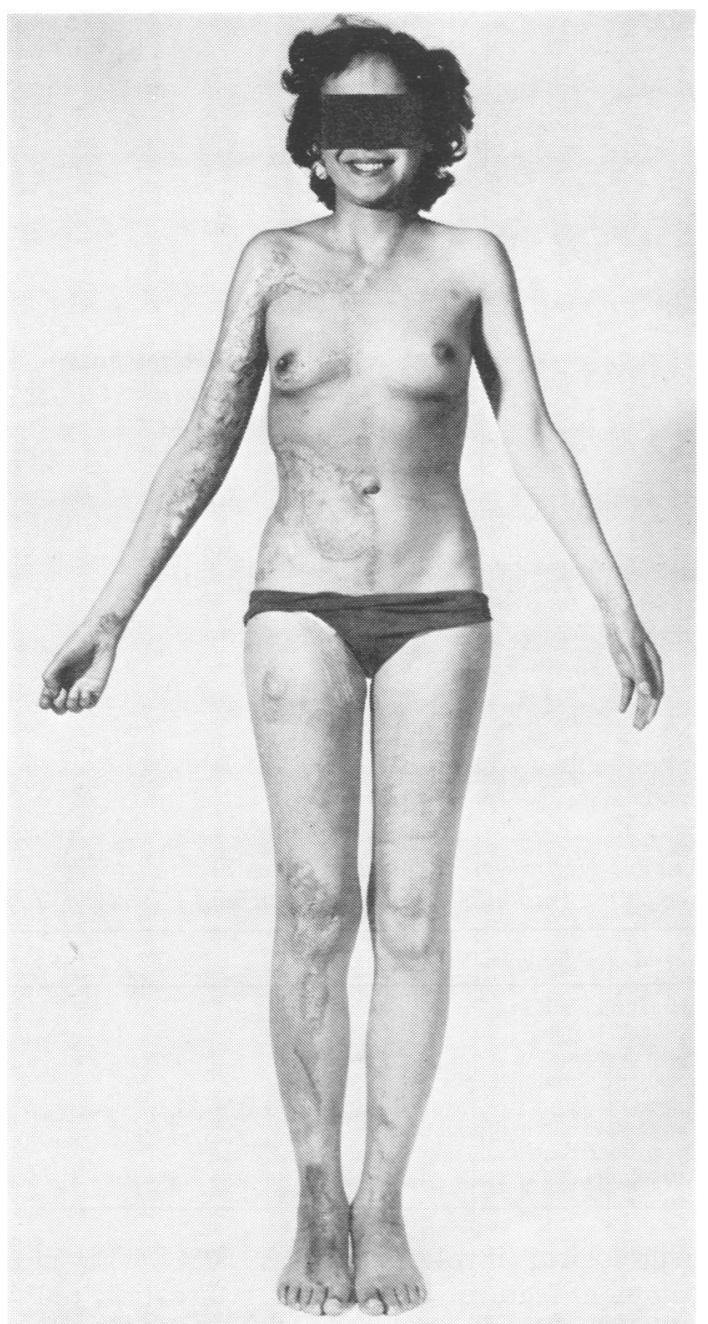

Fig. 1 Frontal view of patient to show extent of cutaneous lesion

She had a motor-type dysphasia on admission. Psychological examination showed errors of transposition, omission, and duplication of phonemes. There was no nominal deficit or difficulty with verbal comprehension but there was a distinct impairment of verbal fluency. These findings suggested a lesion of the dominant hemisphere, probably the right in her case. Her verbal IQ was 85 and performance IQ 84 on the Weschler Adult Intelligence Scale.

There was a partial right sixth cranial nerve palsy. The vessels of the right retina were anomalous, unusually tortuous, and slightly larger than those on the left. The number of disc capillaries was increased. There was also a prominent superior conjunctival vessel joining an abnormal leash of vessels in the outer canthus, forming a small tumour. This lesion (probably a haemangioma) was not biopsied. There were several prominent conjunctival vessels in the lower half of the globe as well. The left eye was normal. Unaided visual acuity, visual fields, intraocular pressure, and ophthalmodynamometry were all normal. The only other neurological abnormality was a left extensor plantar response.

All the peripheral pulses were palpable. The blood pressure in both arms was equal. She had a soft ejection systolic murmur in the mitral and pulmonary areas. There was a loud harsh sysiolic bruit over the right vertebral artery.

Relevant radiological investigations showed a hypoplastic right lung with extensive pleural reaction, rib notching on the right side, a small right clavicle, thinning of the right skull vault, and a large right hand. A computerised axial tomogram scan showed an enlarged fourth ventricle with a small discrete area of calcification of unknown significance behind and slightly to the right of it. There was no enhancement with intravenous injection of contrast medium, and no other abnormality. Four vessel angiography, a month after the onset of dysphasia, demonstrated an occluded right internal carotid artery in the neck (Fig. 2), and normal intracranial vessels with good collateral circulation. The other major vessels of the aortic arch were normal, except for a slight kinking of the right subclavian artery. Catheterisation of the right side of the heart confirmed normal intracardiac pressures and the absence of a shunt. The previous pulmonary angiogram findings were also confirmed, and numerous collateral vessels were seen. The aorta was normal but the right coronary artery arose aberrantly from it. The cause of these appearances was uncertain but was consistent with either the effects of longstanding inflammatory disease affecting the right lung and pleura, or with a congenital anomaly of the right pulmonary vessels and lung.

During the patient's admission her speech improved rapidly. She is now receiving speech therapy as an outpatient.

\section{Discussion}

The "epidermal naevus syndrome" consists of a typical skin lesion, usually unilateral, associated with the abnormalities already listed. Most case reports have been isolated examples (Von Schimmelpennig, 1957; Feuerstein and Mims, 1962; 


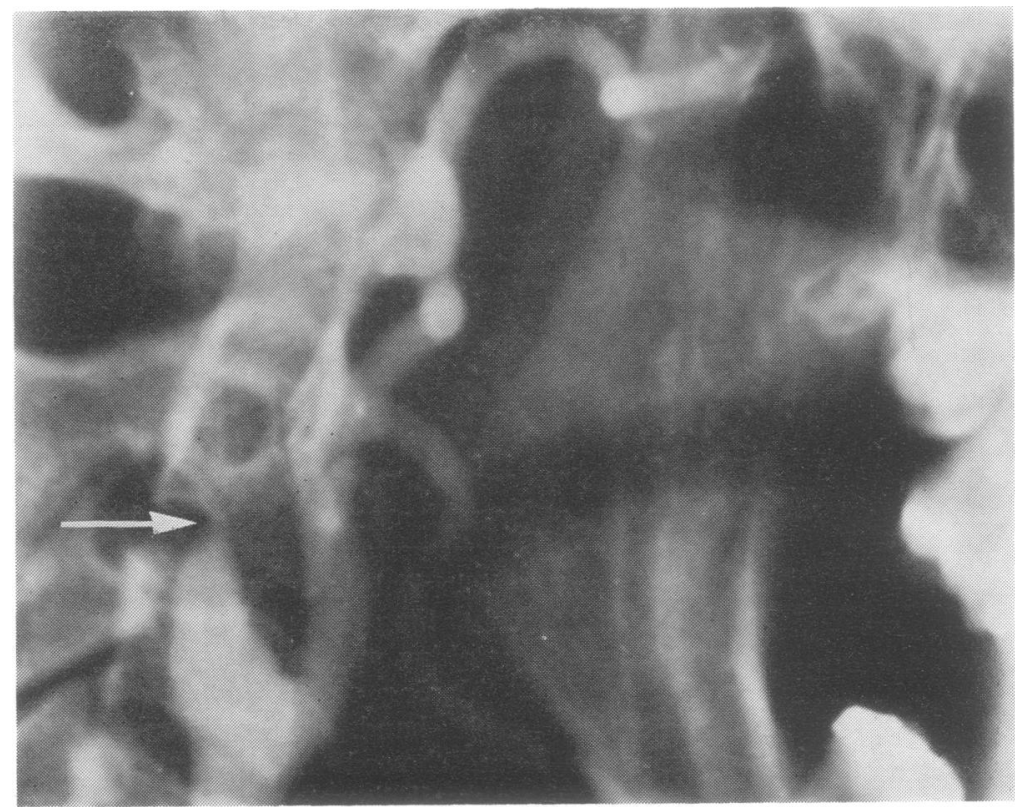

Fig. 2 Carotid angiogram demonstrating occlusion of right internal carotid artery (arrowed).

Gange and Boon, 1977), although there have been at least two attempts at case collection (Larrègue et al., 1974; Solomon and Esterly, 1975).

There is a wide variety of cutaneous manifestations of the epidermal naevus syndrome including several varieties of epidermal naevi, organoid (adnexal) naevi, pigmentary disturbances, vascular and fibrovascular lesions which may occur separately or in combination. The most common skin manifestation is naevus unius lateris, a long linear warty streak, but at least a third of patients have a mixture of lesions (Solomon and Esterly, 1975). These authors have argued that the multiple cutaneous manifestations are variants of the same process. The confusing variety of dermatological descriptive terms probably serves little purpose.

Although our patient's skin biopsy specimens (obtained during her plastic surgery operations) had originally been reported as showing seborrhoeic keratoses, a review of the biopsy histology showed all the typical histological features of the epidermal naevus syndrome.

The skeletal abnormalities and hypoplastic lung present in this patient have been described previously. We have not been able to find previous mention of pulmonary angiographic details nor description of intestinal lymphangiectasia in association with this syndrome.

In Solomon and Esterly's (1975) series of 60 cases various accompanying neurological features were noted (Table). The overall incidence of
Table Neurological features of epidermal naevus syndrome (modified from Solomon and Esterly, 1975)

Neurological features

Mental retardation

Cortical atrophy

Hydrocephalus

Focal and grand mal epilepsy

Hyperkinesia

Cerebrovascular malformations

Cranial nerve and cranial nuclear abnormalities

Astrocytoma

neurological involvement was $50 \%$. The most common feature was mental retardation $(40 \%)$ which has been widely reported in the literature. Epilepsy was also common, occurring in $30 \%$ of cases.

While cerebral vascular malformations have been reported, there is no previous report of a vascular occlusion. We suggest that the right carotid artery was dysplastic. The unilateral nature of the abnormalities in the right pulmonary arteries, the right coronary artery, and the right retinal and conjunctival vessels would strongly support this. Apart from the predominantly left sided Raynaud's phenomenon, all the underlying abnormalities and the naevus itself were right sided. The duration of the carotid occlusion is radiologically indeterminate; we presume it was recent and preceded the ictus, but not of sufficiently longstanding to account for the ocular vascular abnormalities. 
Ocular complications were found in a third of Solomon and Esterly's series. Complications described include extension of the naevus into the conjunctiva, subconjunctival lipodermoids, corneal opacities and pannus formation, coloboma of the lid, iris, choroid or retina; antimongoloid lid fissures; ectopic lacrimal glands; generalised retinal degeneration; nystagmus; isolated third nerve palsies; esotropia and teratomas of the orbit (Haslam and Wirtschafter, 1972). Cases 1 and 2 described by Holden and Dekaban (1972) both had haemangiomas involving the sclera as our patient probably did. Our patient also had a partial sixth nerve palsy.

The occurrence of a high incidence of neurological and ocular abnormalities together with the various other associated abnormalities and the increased risk of neoplasia make this an important syndrome to recognise. Cerebral vascular complications may arise as a result of occlusion of vessels or, more commonly, because of haemorrhage from vascular anomalies or malformation.

We would like to thank Mrs K. Fischel for help with translation of literature.

\section{References}

Feuerstein, R. C., and Mims, L. C. (1962). Linear nevus sebaceus with convulsions and mental retardation. American Journal of Diseases of Childhood, 104, 675-679.

Gange, R. W., and Boon, A. W. (1977). Epidermal naevus syndrome. Proceedings of the Royal Society of Medicine, 70, 282-283.

Haslam, R. H. A., and Wirtschafter, J. D. (1972). Unilateral external oculomotor nerve palsy and nevus sebaceous of Jodassohn. Archives of Ophthalmology, 87, 293-300.

Holden, K. R., and Dekaban, A. S. (1972). Neurologic involvement in nevus unis lateris and nevus linearis sebaceus. Neurology (Minneapolis), 22, 879887.

Larrègue, M., Cosgas, B., Masclef, P., and Solignae, J. (1974). Le syndrome du naevus epidermique de Solomon. Annales Dermatologie et de Syphiligraphie (Paris), 101, 45-55.

Solomon, L. M., and Esterly, N. B. (1975). Epidermal and other congenital organoid nevi. Current Problems in Paediatrics, VI.

Von Schimmelpennig, G. W. (1957). Klinischer Beitrag zur Symptomatologie der Phakomatosen. Fortschritte auf dem Gebiete der Rontgenstrahlen und der Nuklarmedizin, 87, 716-720. 